\title{
A Study on the Ship Energy Efficiency \& GHG Emission Control in China
}

\author{
Wang Yong ${ }^{1}$, Hou Guobin ${ }^{2, *}$ \\ ${ }^{1}$ School of International Law, East China University of Political Science and Law (ECUPL), Shanghai, China \\ ${ }^{2}$ School of International Law of East China University of Political Science and Law, Shanghai, China
}

Email address:

wangyong@ecupl.edu.cn (Wang Yong), hou_bin@163.com (Hou Guobin)

${ }^{*}$ Corresponding author

\section{To cite this article:}

Wang Yong, Hou Guobin. A Study on the Ship Energy Efficiency \& GHG Emission Control in China. International Journal of Environmental Protection and Policy. Vol. 8, No. 3, 2020, pp. 52-58. doi: 10.11648/j.ijepp.20200803.11

Received: June 3, 2020; Accepted: June 28, 2020; Published: July 7, 2020

\begin{abstract}
Greenhouse gas emissions from the shipping industry are one of the important causes of global climate change. Marine transportation, although indispensable and has made a significant contribution to economic development, emits about 940 million tons of carbon dioxide (CO2) each year, accounting for about $2.5 \%$ of global greenhouse gas (GHG) emissions according to the Third IMO GHG Study 2014. As one of the major shipping nations, China has been committed to solving the problems of GHG control through extensively global cooperation with international organizations and other countries at all times. China has also continuously improved domestic legislation and strengthen law enforcement for the purpose of reducing gas emissions from shipping since the year of 2000. Although China has made quite a number of achievements in energy saving and GHG emission reduction in the shipping industry. on the road to green shipping, China still faces various problems and challenges. By analyzing the status of shipping industries and the practices in GHG control in shipping sector in China and discussing the obstacles in the Improvement of Ship EE \& GHG Emission Reduction and Evaluations under the current circumstance, this paper proposed further actions to be taken to reduce GHG emissions in shipping sectors in China.
\end{abstract}

Keywords: Energy Efficiency, GHG Emission Control, Shipping, Climate Change

\section{Introduction}

The ocean is a strategic space to support global economic development in the future, as well as the important engine to boost the growth of global economy. According to the conservative estimate of Organization for Economic Cooperation and Development (OECD), the total value of the global marine economy increased in 2010 was $\$ 1.5$ trillion, which will rise to $\$ 3$ trillion in 2030. The ocean is the source of food and livelihoods for billions of people worldwide [1]. It is vital to the survival and development of all humankind to strengthen marine governance and promote sustainable marine development.

Human activity is one of the most important factors affecting the marine ecological environment, and the impact caused by the shipping industry cannot be ignored. The discharge of pollutants from the shipping industry is a serious threat to the marine environment, leading to the continuous deterioration of the marine environment, aggravating the decline of marine fishery resources and the decline of marine biodiversity. Greenhouse gas emissions from the shipping industry are one of the important causes of global climate change. Marine transportation emits about 950 million tons of carbon dioxide $\left(\mathrm{CO}_{2}\right)$ each year, accounting for about $2.5 \%$ of global greenhouse gas (GHG) emissions [2]. If marine greenhouse gas emissions by sea are considered to be from a country, it will be the fifth largest emitter in the world. If no effective measures are taken to curb current situation, Such emissions are expected to increase significantly. If change doesn't happen, Gas emissions from the maritime industry will increase by $50 \%$ or even $250 \%$ by 2050 , which will greatly impair the basis targets of the Paris Agreement.

As a major shipping power, China has always been committed to participating in marine environmental protection, seeking international cooperation, and striving to improve energy efficiency and reduce greenhouse gas emissions. In this paper, the author will give a detailed description of the shipping industry, the relevant conventions and laws on the 
ocean environment protection and the efforts made by all parties, analyses the challenges faced by china in the improvement of ship EE \& GHG Emission reduction and evaluations and finally put forward proposed actions to be taken in terms of the ship EE \& GHG Emission reduction.

\section{Analysis of Status of Shipping in China}

\subsection{Shipping Fleet}

With the rapid development of national economy and trade, China's maritime transport industry has witnessed a fast step forward, and now China has become one of the most important maritime countries in the world. About $90 \%$ of China's foreign trade is carried out by sea. China controls $8.87 \%$ of the total capacity of the world's merchant fleet, By
2030, China's total shipping capacity will account for more than one-third of the total [3]. The Chinese flag ships account for $4.2 \%$ of the world's merchant fleet, ranking eighth among the world's major flags.

1) Status of all type of vessels in China

According to "Statistics Bulletin on Transport Industry Development 2017," issued by the Ministry of Transport of China, by the end of year 2017, China has 144,900 ships used for transportation on water, decreased by $9.5 \%$ than the previous year; Net dead weight 256.5163 million tons, decreased by $3.6 \%$ than the previous year; Passenger capacity 967,500 persons, decreased by $3.5 \%$ than the previous year; container capacity 2.163 million TEUs, increased by $13.2 \%$ than the previous year. See table 1 below "Composition of waterborne transport vessels owned by China, 2017".

Table 1. Composition of waterborne transport vessels owned by China, 2017, (By area of navigation).

\begin{tabular}{llll}
\hline \multicolumn{2}{l}{ Composition of waterborne transport vessels owned by China, 2017, (By area of navigation) } & Actual performance & Increment over the previous year (\%) \\
\hline Index & Unit & & 13.23 \\
\hline Inland water transport vessels & & 13149.73 & -10.1 \\
Number of vessels & ten thousand & 72.30 & -1.6 \\
Net deadweight & ten thousand tons & 32.48 & -6.6 \\
Passenger capacities & ten thousand & & 9.3 \\
Container capacity & ten thousand TEUs & 10318.00 & -1.9 \\
Coastal vessels & & 7044.41 & 4.5 \\
Number of vessels & ten thousand & 22.36 & 9.9 \\
Net deadweight & ten thousand tons & 50.17 & 19.7 \\
Passenger capacities & ten thousand & & -4.3 \\
Container capacity & ten thousand TEUs & 2306.00 & -16.3 \\
Ocean-going vessels & & 5457.50 & -13.7 \\
Number of vessels & ten thousand & 2.08 & 11.9 \\
Net deadweight & ten thousand tons & 133.66 & \\
Passenger capacities & ten thousand & ten thousand TEUs & \\
Container capacity & & \\
\hline
\end{tabular}

2) Status of coastal inter-provincial vessels in China

Compared with the end of year 2016, the capacity of different types of coastal vessels in China has maintained a certain increase, and the average age of ships is about 10 years.
The details are shown below and summary status is listed in table 2 "Summary status of coastal inter-provincial vessels in China".

Table 2. "Summary status of coastal inter-provincial vessels in China".

\begin{tabular}{|c|c|c|c|c|c|}
\hline \multirow[b]{2}{*}{ Vessel type } & \multicolumn{5}{|c|}{ Status of coastal inter-provincial vessels in China } \\
\hline & Total number & $\begin{array}{l}\text { Total capacity (deadweight } \\
\text { or TEUs) }\end{array}$ & $\begin{array}{l}\text { Tonnage increment } \\
\text { compared with } 2016\end{array}$ & $\begin{array}{l}\text { Number of vessels } \\
\text { withdrawn from the market }\end{array}$ & $\begin{array}{l}\text { Average age } \\
\text { (years) }\end{array}$ \\
\hline Dry bulk carriers & 1671 & 55.22 million tons & $2.78 \%$ & 159 & 9.07 \\
\hline Container ships & 195 & 605,200 TEUs & $3.95 \%$ & 35 & 10.21 \\
\hline Oil tankers & 1316 & 10.09 million tons & $1.57 \%$ & 108 & 9.21 \\
\hline Chemical tankers & 272 & 1.06 million tons & $2.55 \%$ & 1 & 9.30 \\
\hline Liquefied gas carriers & 72 & 0.245 million tons & $10.90 \%$ & 0 & 10.45 \\
\hline
\end{tabular}

Table 2. Continued.

\begin{tabular}{lllll}
\hline \multirow{2}{*}{ Vessel type } & \multicolumn{2}{l}{ Status of coastal inter-provincial vessels in China } & \\
\cline { 2 - 5 } & Number of old vessels & $\begin{array}{l}\text { Number of specially } \\
\text { inspected vessels }\end{array}$ & $\begin{array}{l}\text { Percentage (Number of } \\
\text { old vessels/ total vessels) }\end{array}$ & $\begin{array}{l}\text { Percentage (Number of specially } \\
\text { inspected vessels/ total vessels) }\end{array}$ \\
\hline Dry bulk carriers & 164 (over 18 years old) & 31 (over 28 years old) & $9.81 \%$ & $1.86 \%$ \\
Container ships & 21 (over 20 years old) & 0 & $10.77 \%$ & $0 \%$ \\
Oil tankers & 274 (over 12 years old) & 13 (over 26 years old) & $20.82 \%$ & $0.99 \%$ \\
Chemical tankers & 48 (over 12 years old) & 1 (over 26 years old) & $17.65 \%$ & $0.37 \%$ \\
Liquefied gas carriers & 18 (over 12 years old) & 3 (over 26 years old) & $25.00 \%$ & $4.17 \%$ \\
\hline
\end{tabular}

Note: Dry bulk carriers: statistical data are based on coastal inter-provincial dry bulk cargo ships more than 10,000 tons, excluding awkward cargo ships, multi-purpose ships and other general cargo ship. 
Container ships: statistical data are based on coastal inter-provincial container ships more than 700TEUs, excluding multi-purpose ships.

\subsection{Legislation and Management}

In order to protect the ocean environment, improve energy efficiency and reduce the GHG emission, china already possessed international conventions and national laws and policies to establish and enforce the standards in shipping industry.

\subsubsection{International Conventions}

1) United Nations Framework Convention on Climate Change (UNFCCC)

The UNFCCC aims to ensure that the concentration of greenhouse gases in the atmosphere is stabilized at a level that protects the climate system from dangerous human interference [4]. This level should be achieved within a time frame sufficient to enable ecosystems to adapt naturally to climate change, to ensure that food production is not threatened and to enable economic development to be sustainable. China is a signatory to the United Nations Framework Convention on Climate change, its Kyoto Protocol and the Paris Agreement. In June 30, 2015, China submitted to the Secretariat of the United Nations Framework Convention on Climate Change $<$ Strengthening Action to deal with Climate change: China's National contribution>. In aspects of the national conditions, the stage of development, the Sustainable Development Strategy and the responsibility assumed, china sets the goal of independent action by 2030 : the Carbon dioxide emissions reach the peak around the year and try to reach the peak as soon as possible in 2030; the unit GDP of carbon dioxide emissions are $60 \%$ to $65 \%$ lower than in 2005, and the proportion of non-fossil energy accounting for primary energy consumption reached about $20 \%$, and the forest volume is increased by 4.5 billion cubic meters over 2005 [5]. Moreover, china will take proactive measure to adapt the climate changes, establishing an effective mechanism and capacity to withstand the risk of climate change in the territories of agriculture, forestry, water resource and in the key areas of cities, coastal areas, and ecologically fragile areas, and gradually improve the forecasting, early warning and disaster prevention and mitigation systems.

The UNFCCC comprises of five basic principles, among which CBDR-RC is the fundamental principle for the international shipping GHG emission reduction law to follow. The CBDR-RC principle mainly provides for the responsibility of each countries when implementing the measures of protecting the global environment. Overall, CBDR-RC should be divided into the following three key words, "common responsibility", "differentiated responsibility", and "Respective Capabilities". Due to the global basis of the influence of climate change, "Common responsibility" requires each country should bear the responsibility. "Differentiated responsibility" derives from the emission history of developed countries. "Respective
Capabilities" puts emphasis on the balance of the responsibility of GHG emission reduction and the capacity of GHG emission reduction [6].

2) International Convention for the Prevention of Pollution from Ships (MARPOL)

The MEPC formulated the frame of international shipping GHG emission reduction, the reduction would be realized through three approaches, technical measures, operational measures and market measures [7]. Among them, technical measures means that from the perspective of ship technology, through the development of internationally general standards and laws to improve the ship's energy efficiency and reduce the GHG emissions by the ship design itself.

The International Convention for the Prevention of Pollution from Ships (MARPOL) is one of the technical measures. MARPOL is the main international convention covering prevention of pollution of the marine environment by ships from operational or accidental causes. The MARPOL Convention was adopted on 2 November 1973 at IMO. The Protocol of 1978 was adopted in response to a spate of tanker accidents in 1976-1977. As the 1973 MARPOL Convention had not yet entered into force, the 1978 MARPOL Protocol absorbed the parent Convention. The combined instrument entered into force on 2 October 1983. On 1 July 1983, China joined the Convention. On 2 October the same year, the Convention took effect. In 1997, a Protocol was adopted to amend the Convention and a new Annex VI was added which entered into force on 19 May 2005.

The Convention includes regulations aimed at preventing and minimizing pollution from ships - both accidental pollution and that from routine operations - and currently includes six technical Annexes, among which the Annex VI is Prevention of Air Pollution from Ships (entered into force 19 May 2005). This Annex Sets limits on Sulphur oxide and nitrogen oxide emissions from ship exhausts and prohibits deliberate emissions of ozone depleting substances; designated emission control areas set more stringent standards for SOx, NOx and particulate matter. A chapter adopted in 2011 covers mandatory technical and operational energy efficiency measures aimed at reducing greenhouse gas emissions from ships. This Annex plays an important role in the prevention of air pollution from ships.

\subsubsection{National Law}

The Energy Conservation Law is enacted in order to promote energy conservation throughout the society, improve energy efficiency, protect and improve the environment, and promote comprehensive and sustainable economic and social development. On 1 November 1997, the 28th meeting of the Standing Committee of the Eighth National People's Congress passed the Energy Conservation Law and it came into force since April 1 2008. Chapter 3 of the Energy Conservation Law is on Reasonable use and Energy conservation, the Section 4 of which provides for transportation energy saving. In this section, top-level design and overall requirements for the transportation industry is put forward to save energy and 
improve the energy utilization efficiency. It is encouraged by the States to develop and promote the use of clean fuels and alternative fuels for petroleum transportation vehicles [8]. Subsequently, On 25 June 2008, the Ministry of Transport adopted "the measures for implementing the $<$ the Energy Conservation Law of the people's Republic of China>" by road and waterway traffic", which clarified the regulations governing the conservation of energy by road and waterway traffic and improving the efficiency of energy utilization.

\subsubsection{Industrial Policies}

At the policy level, the State Council formulated $<$ Programme of work for the control of greenhouse gas emissions in the Thirteenth Five-Year Plan>, in which the construction of low-carbon transportation system is emphasized. At present, the Ministry of Transport is working out the "13th Five-Year Plan" to control GHG emissions in transportation industry in order to speed up the construction of green and low-carbon transportation system and support the implementation of $<$ the Paris Agreement. $>$ [9]. In addition, in order to speed up the structural adjustment of the shipbuilding industry and the shipping industry, the State Council has successively issued the "Implementation Plan for speeding up the structural Adjustment of the Shipbuilding Industry to promote Transformation and upgrading (2013-2015)" and the "Guidance on the resolving contradiction of serious overcapacity"; Four ministries and commissions, including the Ministry of Transport, the Ministry of Finance, the Development and Reform Commission, and the Ministry of Industry and Information Technology, have also issued the "Plan for the early scrapping and updating of old Transport vessels and single hull tankers," which have eliminated a large number of old transport vessels and single-hull tankers with high energy consumption and high risk of safety and pollution. These measures have played an significant role in promoting energy saving and emission reduction and environmental protection.

As a Party to Annex VI of the MARPOL Convention, China has actively promoted the domestication of the relevant provisions of the rules on energy efficiency of ships by issuing effective notices and revising the Technical Rules for Statutory Survey of Oceangoing Vessels to incorporate relevant domestic requirements. Good conditions and background have been created for the implementation of the ship's energy efficiency rules. Meanwhile, the MSA of the Ministry of Transport has led the development of the "Guidelines for Port State Inspection of the Energy Efficiency Rules for Ships in Chapter IV of Annex VI to the MARPOL Convention" under the framework of the Tokyo memorandum, The China Classification Society (CCS) has also developed relevant technical specifications to provide services for authorized statutory surveys and class surveys for ships and provide guidance for the development and application of China's green shipping technology, optimization and upgrading of ship industry and shipping industry structure, and construction of energy efficiency management system for shipping enterprises [10].
While fully implementing the IMO ship energy efficiency regulations, the Ministry of Transport has further strengthened the building capacity of energy saving and GHG emission reduction of shipping enterprises and ships through the establishment of technical standards, incentive mechanisms, and special actions, etc. China has formulated recommended standards, including < the Fuel Consumption Limits and Verification Methods for Operating Ships $>$ and $<$ the $\mathrm{CO}_{2}$ emission limits and verification methods for operating ships $>$. The Ministry of Transport, together with the Ministry of Finance, issued $<$ the Interim Measures for the Management of Special Funds for Energy Saving and Emission Reduction in Transport $>$, and $<$ the guidance on Promoting the Application of Liquefied Natural Gas in the Water Transport Industry $>$ and $<$ Pilot Demonstration Project for Application of Liquefied Natural Gas in Water Transportation Industry>, and have carried out special action on low - carbon transportation of " vehicles, ships, roads and ports ", continuously enhancing the consciousness of enterprises on energy saving and emission reduction, increasing the governmental investment on energy saving and emission reduction, exploring alternative energy sources, and promoting energy efficiency standards.

\subsubsection{Port State Inspection}

As the competent authority of port state inspection the State Maritime Administration has one of the important purposes to prevent marine pollution, and the outstanding performance is the supervision of the low-carbon maritime treaty and the supervision of low-carbon green standards during the construction of the fourth-generation port [11]. China is a member of the Tokyo Memorandum and has played an active role in regional cooperation in port state inspection in compliance with international conventions. In 2015, the China Maritime Administration led the development of $<$ the guidelines for Port State Inspection of Chapter IV of the MARPOL Convention Annex VI>, under the framework of the Tokyo Memorandum of Understanding, which was issued to all members by "Note of Attention for PSCO officers, No. 7/March 2015" and provided guidance for all party members to unify and effectively carry out port state inspection on the ship energy efficiency.

\subsection{Application of Ship EE \& GHG Emission Reduction Technologies in Current Stage}

\subsubsection{In the Ports}

In order to implement the concept of scientific development in depth, and to build energy resource saving and environment-friendly waterway transportation, China has implemented a series of measures to save energy and reduce emissions in port operation, including raising the awareness of energy conservation and emission reduction among all port staff and workers, and optimizing port design. strengthen port energy saving management, apply advanced technology and eliminate backward technology, improve energy saving system and strengthen propaganda and training [12].

For the newly built port, the cargo handling technology and equipment are optimized, the low energy consumption and 
high efficiency equipment are selected, and the equipment with electric energy as the power source is preferred.

For the existing port, the old equipment with high energy consumption and low efficiency will be replaced step by step to raise the whole technical level of equipment and reduce energy consumption and exhaust gas emission. Energy change from oil into electricity are applied gradually.

Optimize the layout of the port area and the design of the wharf, use the information technology, strengthen the scientific production scheduling of the port, and optimize the structure of the transport organization.

Actively promote green lighting engineering, scientific and reasonable control of illumination in port area.

For oil and gas terminals and terminal refueling stations, advanced oil and gas recovery techniques and devices are encouraged to collect oil and gas from wharves and terminal refueling stations during storage and transportation of the oil, to eliminate the hidden dangers of oil and gas volatilization.

Encourage renewable resource utilization, use solar energy to provide hot water, research and utilize tidal energy, and set up small wind energy utilization device.

\subsubsection{In the Shipping Companies}

As shown in chapter 2, the average age of the ships owned or operated by Chinese shipping companies is around 10 years. Compared with the shipping companies in developed countries, the application level of energy efficiency technology of Chinese shipping companies is relatively low, but compared with that of other developing countries, the level of energy efficiency utilization is relatively high. In recent years, in order to promote energy saving and GHG emission reduction, the Chinese government has formulated a series of regulations and policies, and increased the introduction, development and application of ship energy efficiency technology. Chinese shipping companies have also stepped up energy efficiency management of ships, actively using ship energy efficiency technologies and advanced energy efficiency management models [13]. The levels of energy efficiency of Chinese shipping companies are increasing rapidly.

\section{Obstacles in the Improvement of Ship EE \& GHG Emission Reduction and Evaluations}

\subsection{Top Level Design Needs to Be Strengthened}

Although both the State and the Ministry of Transport have introduced and developed the 13th Five-Year Plan for the Control of greenhouse Gas emissions, there is a lack of an overall strategy and implementation programme at the maritime transport industry level. The systematic and forward-looking deployment of marine energy efficiency and greenhouse gas emission control needs to be strengthened, and development goals and priorities need to be further clarified.

\subsection{Basic Work Still Needs to Be Rammed}

Although the relevant energy consumption monitoring and statistical system established by the Ministry of Transport provides a certain data basis for the evaluation of maritime energy consumption and emissions, the coverage of the marine energy consumption monitoring and statistical system, statistical methods and detailed requirements need to be further improved in order to master the basic data of maritime energy efficiency and emissions and provide effective support for related management and decision-making.

\subsection{The Levels of Energy Efficiency Management in Shipping Industries Are Varying}

The level of energy efficiency management in the industry is uneven, and some shipping companies, especially small and medium-sized shipping companies and their employees, have weak awareness of energy efficiency management and weak management level [14]. There is a lack of communication and cooperation among shipping companies in research and development and application of energy efficiency technologies. Affected by the bad shipping market, shipping companies have insufficient investment in improving ship energy efficiency through technical means.

\subsection{Existing Raising Rate of the Vessels' Energy Efficiency Needs to Be Reduced}

$<$ The Enhanced Action on Climate change-China's National Independent Contribution> submitted by China to the United Nations proposed that $\mathrm{CO}_{2}$ emissions reach to peak by around 2030 and strive to reach the peak as soon as possible. In 2014, China and US signed mutually the China-US Joint Announcement on Climate Change, which Signifies that China-US cooperation on climate change has entered a new height and embodies the determination of the highest decision-makers of China and the United States to promote low-carbon emission reduction [15]. In the Announcement, China intends to achieve the peaking of $\mathrm{CO} 2$ emissions around 2030 and to make best efforts to peak early and intends to increase the share of non-fossil fuels in primary energy consumption to around $20 \%$ by 2030 . However, according to the prediction, if the vessels' energy efficiency in China is still maintaining the existing raising rate, the total amount of $\mathrm{CO}_{2}$ emission will exceed 19.19 million tons by 2020 for the coastal vessels, and reach to 22.99 - 24.34 million tons by 2030. It is very difficult to reach the peak value. For ocean-going vessels, $\mathrm{CO}_{2}$ emissions will be about 34.9-37.3 million tons by 2020 and 38.5-49.2 million tons by 2030 . Facing new targets to address climate change, the maritime industry must accelerate its low-carbon development process and adopt more proactive energy efficiency management and emission reduction measures to participate in the global climate change governance system to provide support for the implementation of the national strategy to combat climate change. 


\section{Proposed Actions to Be Taken}

Based on the present status of GHG emission control and obstacles faced by China in further promotion of measures to tackle the problem of climate change in shipping sectors, this paper put forward the following proposals to be taken:

1) Further improve the relevant reporting system to lay the foundation for the determination and prediction of the shipping energy efficiency and the establishment of GHG emission baseline

China transport departments have established a relatively complete system of regular statistical reporting, including the comprehensive statistical report system for transportation, the comprehensive statistical report system for ports, the statistical report system for fixed assets investment in traffic, statistical report system for energy consumption monitoring of transportation, statistical report system for survey of water traffic situation, etc. However, because there are many subjects involved, the number of data is huge, and the unified electronic data exchange platform has not yet been established, it brings some difficulties for the comprehensive collection and in-depth analysis of the basic data. In addition, the design of these systems mainly considers the domestic management needs and habits, and the design of some reports needs to be strengthened in connection with the requirements of relevant international conventions. In view of the problems existing in the current data base and considering the development of the current big data acquisition, storage and analysis technologies, it is suggested that the scope of statistical data be further expanded, and adjust and refine statistical data categories as far as possible in accordance with the relevant provisions of international conventions and statistical customs. At the same time, the unified and fast EDI platform should be set up and the corresponding data verification mechanism should be established to ensure the completeness, accuracy and reliability of the data.

2) Establish an inventory and incentive mechanism for energy efficiency enhancement and GHG emission reduction in existing operating ships, and promote energy-saving and emission reduction technologies

In order to substantially improve the energy efficiency of existing operating ships and reduce greenhouse gas emissions, it is recommended that a systematic study be carried out for different types of vessels, and produce a list of technically feasible and cost-effective technologies in order to provide a reference for shipping companies to carry out the technical transformation. Meanwhile, in view of the different concerns of the relevant stakeholders on the energy efficiency level of the ship under different charter modes, it is recommended to actively explore the innovative business operation mode or mechanism, and strive to make the promotion of the energy efficiency of the ship become the common concern of all stakeholders, so as to eliminate or reduce the obstacles in the promotion and application of energy saving and emission reduction technologies.

3) Speed up the process of domestication of ship fuel consumption data collection mechanism and encourage shipping companies to implement it

In order to effectively implement the amendment to Annex VI of the MARPOL Convention on the data collection mechanism on the fuel consumption of ships, it is suggested that the authorities should carry out domestic publicity as soon as possible and issue the effective public notice in a timely manner; At the same time, as soon as possible, revise and adopt documents such as the $<$ Technical code for statutory survey of international ships $>$, and incorporate the establishment of a data collection mechanism for ship fuel consumption into the relevant national norms and requirements, so as to encourage companies to implement it ahead of time, and require domestic ships to implement synchronously; Meanwhile, continue to maintain close communication and cooperation with the Tokyo Memorandum Organization to further strengthen regional cooperation in port state inspection for the implementation of international conventions.

\section{Conclusion}

With the rapid development of national economy and trade, China's maritime transport industry has witnessed a fast step forward, and now China has become one of the most important maritime countries in the world. About $90 \%$ of China's foreign trade is carried out by sea. However, GHG emissions from shipping sectors have become a great concern in China. Being accountable to the whole world and human beings, although China has made great steps forward in tackling the problem of climate change in all aspects, particularly in shipping sectors, on the road to green shipping, China still faces the various problems and challenges. Further effective and reasonable measures shall be taken towards the green shipping, including: further improvement of the relevant reporting system, establishment of GHG emission baseline, establishment of an inventory and incentive mechanism for energy efficiency enhancement and GHG emission reduction, and speeding up the process of domestication of ship fuel consumption data collection mechanism, etc.

This paper is the phased achievement of the key project "the community of shared future of the ocean and the development of international law of the sea" in the field of marine development research of China Ocean Development Foundation and China Ocean Development Research Center in 2019.

\section{References}

[1] http://www.cciced.net/xwZx/hfyw/201906/t20190619_100115. html.

[2] Smith, T. W. P, Jalkanen, J. P, Anderson, B. A, etc. Third IMO Greenhouse Gas Study 2014 [J]. 2015.

[3] Hu xianjin. China's total shipping capacity will account for more than one-third of the world's shipping capacity By 2030, [J]. Maritime Intelligence, 2013, 000 (010): P. 2-2. 
[4] Dawson B , Spannagle M. United Nations Framework Convention on Climate Change (UNFCCC) $[\mathrm{J}]$. Complete Guide to Climate Change, 2009, 108 (8): A353-A353.

[5] http://www.china.org.cn/chinese/2015-07/01/content_3595359 0.html.

[6] Yuan zhenhua. On the principle of Common But Differentiated Responsibilities in international law. Journal of Chongqing University of technology, p78-79.

[7] Ren weimin. Study on international laws governing the reduction in greenhouse gas emission from shipping. Annual of china maritime law, 2011, $22(3), \mathrm{p} 4$.

[8] The Energy Conservation Law of the people's Republic of China. Article 46. http://www.pkulaw.cn/fulltext_form.aspx?Db=chl\&Gid=f5ee1 eeb0f595353bdfb\&keyword=\%e4\%b8\%ad\%e $5 \% 8 \mathrm{~d} \% 8 \mathrm{e} \% \mathrm{e} 4$ $\%$ ba $\%$ ba $\%$ e6\%b0\%91\%e5\%85\%b1\%e5\%92\%8c\%e5\%9b\%b d $\%$ e $8 \% 83 \%$ bd $\%$ e6\%ba\%90\%e8\%8a\%82\%e7\%ba\%a6\%e6\% b3\%95\&EncodingName $=\&$ Search_Mode $=$ like\&Search_IsTitl $\mathrm{e}=0$.

[9] Ma zhongyu, Xiao hongwei. The aim and the strategy of the control of Carbon Dioxide Emission in China during the 13th Five Year. Energy of China. 2016, 038 (003): 14-18, 13.
[10] Xing dan. CCS: Pioneer in Green Shipping [J]. China Ship Survey, 2011 (08): 38-40, p39.

[11] Wang shumin, Su yidan, Wang hanchen. Research on Port State Supervision under the Scope of Implementation of Low-Carbon Shipping Treaty [J]. Journal of Dalian Maritime University, 2014, 13 (04): 69-74, p69.

[12] Peng chuansheng. Thoughts and Arrangements for the Work of Energy Saving and Emission Reduction in the "12th Five-Year Plan" of Chinese Ports [J]. China Ports, 2011, 000 (005): 1-4, 9.

[13] Li biying. The current situation of energy saving and emission reduction in shipping industry and its low-carbon development approach [J]. Journal of Engineering Studies, 2012, 000 (003): 260-269, p262.

[14] Xu chunming. Study on the current status and countermeasures of ship energy saving [J]. Technology Outlook, 2016, 26 (15), p282.

[15] Huang yongfu. Prospects and countermeasures for the relationship between China and the United States in responding to global climate change [C]. China economic analysis \& outlook (2015 2016), China International Economic Exchange Center, 2016: 375-391, p373. 